\title{
A Far Cry from School History: Massive Online Open Courses as a Generative Source for Historical Research
}

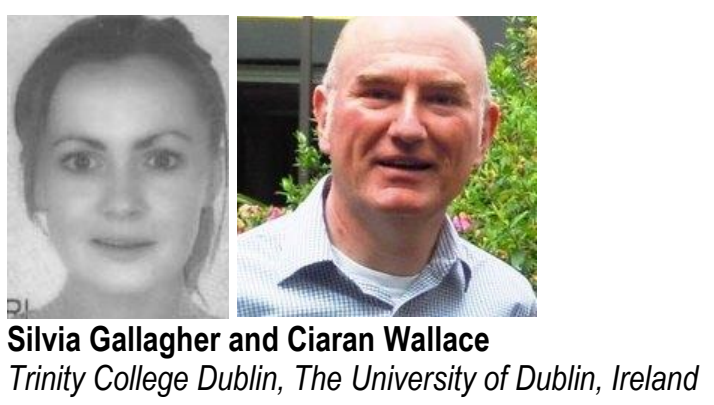

\begin{abstract}
Current research into Massive Online Open Courses (MOOCs) has neglected the potential of using learner comments for discipline-specific analysis. This article explores how MOOCs, within the historical discipline, can be used to generate, investigate, and document personal narratives, and argues that they serve as a rich platform for historical resource generation. Through these narratives, this research explores changing perceptions of learning; from learning history at school to learning about history in a MOOC. This exploration uses a qualitative thematic analysis of learner comments related to personal narratives of learning history at school from the Trinity College Dublin/Futurelearn "Irish Lives in War and Revolution: 1912-1923" MOOC. These personal narratives were generated both directly and indirectly through four pedagogical tools; reflective questions, multimedia resources, external links, and inter-learner interaction. Broad themes emerged from the analysis of personal narratives including attitudes toward history at school, biased and inadequate teaching, and MOOC teaching compared with school experiences. The analysis demonstrated that MOOCs serve as a generative repository for personal and family historical narratives, and described how MOOCs can change perceptions of teaching and learning history. This paper contributes a novel understanding of MOOCs for discipline-specific analysis, provides a framework for MOOC historical resource generation, and describes changing perceptions of learning from the perspective of MOOC learners.
\end{abstract}

Keywords: Massive online open course, history, public history, oral history, learner comments, resource generation 


\section{Introduction}

Research into Massive Online Open Courses (MOOCs) is at a relatively early stage, and has focused on key areas including pedagogical theory, technological solutions to education, conceptual issues, openness, student engagement and motivation, institutional objectives, and case studies (Liyanagunawardena, Adams, \& Williams, 2013; Sangrà, González-Sanmamed, \& Anderson, 2015). These new online learning spaces offer wide opportunities for many research avenues, but have mainly been concentrated in the educational theory, computer science and online learning domains (Ebben \& Murphy, 2014). This article argues that an important research focus has been neglected by current studies and moves away from existing research to explore MOOCs in terms of the Humanities and how this content can offer new knowledge to the historical discipline.

Previous research into history and learning with technology have explored the challenges of teaching history in media such as virtual realities (Allison, 2008), television (Bage, 1997), and CD-ROMs (Hillis, 2008). Nonetheless, no research has explored the impact of MOOCs on history and little, if any, research has been conducted on what they can contribute to historical research. Contributions by learners in history MOOCs, in particular, have shed light on oral narratives within the historical discipline and the importance placed on them, and these should be examined. The objectives of this research are to explore how MOOCs within the historical discipline can be both a platform for teaching history and also for generating historical narratives through learner comments. This could have important implications for Oral History and Public History research, and for MOOC development. Thus, this research explores learner comments from the Trinity College Dublin/Futurelearn "Irish Lives in War and Revolution: 1912-1923" history MOOC to assess the potential benefits for historical research, especially in the field of Oral History. The contentious nature of this period heightens the value of these learner comments as a resource for exploring the relationship between the public and history, helping us understand how Public History narratives are formed.

\section{Learner Interactions in Massive Open Online Courses}

Massive Open Online Courses (MOOCs) are a relatively new learning phenomenon where learners access freely available online educational multimedia materials, and connect with large numbers of other learners via social engagement tools such as discussion forums (Liyanagunawardena et al., 2013). Online educational materials, such as videos, glossaries, public repositories, images, and timelines serve as pedagogical tools within a structured course platform, and assessment is conducted via formative quizzes, peer review, essays, and responses to open questions (Glance, Forsey, \& Riley, 2013). MOOCs have been hosted on a wide variety of different commercial platforms that allow for open resources and course teaching to be structured in one location (e.g., Coursera, edX, and Futurelearn). These platforms facilitate discussion forums used by learners to comment on course content and share knowledge with one another, and by educators to support social learning, foster community, and promote learner retention (Brinton et al., 2013).

Learner participation in MOOCs is a two way process whereby learners are both consumers and producers of knowledge (Wheeler \& Gerver, 2015). In these connectivist environments, learners are not only being encouraged to interact with one another, but are also given the facility to share and create content (Wang, Chen, \& Anderson, 2014). This research explores how learners in a history MOOC are creating content in the MOOC space by means of personal narratives. 
MOOCs have been heralded as potentially "massive" research laboratories (Diver \& Martinez, 2015). They generate large amounts of learner data in the form of participant activity and interactions (Huang, Dasgupta, Ghosh, Manning, \& Sanders, 2014; Seaton, Bergner, Chuang, Mitros, \& Pritchard, 2014), learner survey results (Fini, 2009), external social media comments (Koutropoulos et al., 2014), interviews (Mackness, Waite, Roberts, \& Lovegrove, 2013), focus groups (Firmin et al., 2014), observations (Grunewald et al., 2013), blog entries (Zutshi, O'Hare, \& Rodafinos, 2013), and forum comments (Tucker, Pursel, \& Divinsky, 2014). These data sources have been analyzed using a wide variety of different qualitative and quantitative methodologies and methods (Gallagher \& Savage, 2016; Raffaghelli \& Persico, 2014) to understand learner behaviour and frame course design, and determine MOOC success or failure. In addition to the strengths of using MOOCs as research laboratories, MOOCs have also been earmarked as having the potential to be research instruments in themselves (Zimmerman, Kopp, \& Ebner, 2016). Furthermore, commentators have coined the phrase Massive Online Open Research (MOOR) to describe the potential of knowledge creation and innovation within large scale collaborative platforms (Machado, Verghese, \& Peltola, 2014). However, although preliminary research has highlighted the potential of MOOCs as research instruments and laboratories, investigating the potential of MOOC forum comments for Oral History research and enquiry has been neglected.

Learner comments on discussion forums are an important component of MOOC research (Gillani \& Eynon, 2014), and have been used to understand user behaviour, motivation, and social integration (Baxter \& Haycock, 2014). These comments include help-seeking from other learners, reflections on course content, emotional vocabulary, clarifications, and personal narratives (Goldberg et al., 2015; Huang et al., 2014; Koutropoulos et al., 2012). Disclosure of personal narrative information in online discussion communities has been found to be an important prerequisite for community membership (Burke, Kraut, \& Joyce, 2010), legitimacy (Galegher, Sproull, \& Kiesler, 1998), and social interaction. Within history MOOCs, learners are encouraged to reflect on historical resources and course content, and it is within these comments that the value of MOOCs for historical research is apparent.

\section{Research Potential of History MOOC Learner Interactions}

Since 2013, there have been over 100 MOOCs focused on history within the Humanities. These range from national-specific content in American, Chinese, Irish, Japanese, African, Latin American, Middle Eastern, European, and British history, to historical eras such as Ancient and Medieval history, and more theoretical and practical history such as historical research and methodology (MOOC-List, 2015). The end goal of these MOOCs is to educate learners about a particular historical topic using open resources, structured pedagogy, and social learning.

The vast array of digital sources available for most periods and themes within the discipline (e.g., social history, labour history, military history, women's history, historical geography, etc.) makes MOOCs especially suitable for teaching history and historical thinking. What might appear, at first glance, to be a rather linear medium more appropriate to direct instructional teaching proves to be very suitable for presenting diverse opinions and conflicting evidence. This challenges learners' preconceptions and presents them with new ways of thinking about "established facts." If all history is constructed and contested, as we constantly remind our undergraduates in the classroom, then MOOCs provide a useful tool and forum for researching and reflecting on evidence, constructing your own analysis, and contesting others. 
Historians use an ever-expanding range of digital humanities resources, many of which are unknown to the general public-who usually have funded them directly or indirectly through state revenue. By introducing a far wider audience to such online resources, MOOCs add value to earlier investment and empower learners of all levels to interrogate primary sources-texts, images, newsreel, and audio clipsin a contextualized way. Humanities MOOCs rely on divergent analyses of any given topic and discussion around the interpretation of a text or an event via these online resources. This encourages reflection on the part of the learners, which can produce valuable insights and revealing interactions with others. It also creates an atmosphere in which learners feel free to contribute new information from their own or their family's experience. It is these interactions and new contributions which are valuable to the historian, particularly to the historian curious about popular constructions of the past, and the origins of versions of the past that people adhere to (Samuel, 1996).

For example, a learner on the "Irish Lives in War and Revolution" MOOC posted a reflection on her grandfather's wartime experience, which included serving as an emergency police recruit in Ireland (a "Black and Tan"), during the Irish War of Independence (1919-1922). This was remarkable for the fact that learners on a standard Irish history courses would rarely-if ever-encounter the Black and Tans, a reviled force in Irish nationalist historiography, through the lens of such a fond familial account. The sheer size and diversity of the MOOC audience made this valuable input possible. Other learners then reflected on the novel realization that even Black and Tans had families and that they had returned to normal life after the conflict.

The unanticipated added value that history MOOCs provide-the creation of a large body of crowdsourced narratives - brings a number of benefits for the discipline. At a basic level, it shows the degree of public interest in history, or in certain elements within it. Beyond this encouraging fact, however, the level of engagement across many thousands of learners demonstrates a strong public awareness around debates and controversies in history. The public, as represented by MOOC learners, is willing to accept that history is complex and is open to multiple interpretations. Learners do not want a populist or "dumbed down" version. Once they are engaged by the material and the course structure, and feel they are operating in a safe and respectful atmosphere, learners feel permitted to share their family or personal narratives.

Previous research on MOOCs has suggested that crowd-sourcing behaviour within these spaces can have a real-world impact (Perifanou, 2014; Prpić, Melton, Taeihagh, \& Anderson, 2015), and this research explores whether crowd-sourced oral narratives can have an impact on historical and educational research. Following Kennedy's (2014) statement that "there is a need for more scholarly research given that MOOCs are a new phenomenon with important implications for online learning in postsecondary institutions," this research explores personal narratives in an Irish History MOOC, and investigates how these narratives, generated through MOOC pedagogical structures, can add value to historical research.

\section{MOOC Learner Interactions for Oral and Public History Research and Enquiry}

The extensive collection of learners' comments presents a methodological challenge for historians. As voluntary unstructured responses to events and images presented on the MOOC, and to invitations to reflect on themes, should they be regarded as an online version of Oral History testimony, as contributions to an accidental crowd-sourcing project, or as individual crumbs of Public history? 
Oral History is a difficult methodology, and good Oral History requires much planning and many hours of intensive field work (Nyhan, Flinn, \& Welsh, 2013). While they cannot, by virtue of the large sample size, be regarded as standardized responses to a uniform Oral History questionnaire or interview, learner comments in the MOOC have a real value for the discipline. They could be regarded as the equivalent of the ephemera collection in many large libraries, which contain huge amounts of small items such as political leaflets, handbills, stickers, receipts, and other material which was never meant to survive, yet gives us such a rich picture of ordinary life in the past. MOOC comments have a distinct advantage as born-digital records: they can be mined for trends and themes far more easily than traditional ephemera, adding significantly to their value. Crowd-sourced history projects such as Europeana, the Imperial War Museum's "Lives of the First World War" in the UK, and the "Letters of 1916" and "Great War Roadshow" in Ireland, acknowledge the importance of original artefacts and of the family stories which surround them. Learner contributions on MOOCs are a logical extension of this practice.

Oral History captures and interprets stories that have been marginalized: the histories of groups who do not control the official record, or who may indeed be the victims of official erasure from the record. The poor, women, the institutionalized, the criminalized, and sometimes just the "unimportant" and ordinary; collectively they may well represent the majority of human experience throughout history, so recording their lives is a vital task. While it would be inaccurate to claim that MOOC learner comments are an automated form of Oral History collection, they can be a very useful addition to the researcher's tool kit.

Learners' comments are a resource in their own right. Echoing the call by Cauvin and O'Neill for "a wider, more inclusive definition of Public History in Ireland. . . one that includes the 'public' as an actor in it" (Cauvin \& O'Neill, 2015), they contribute to this discipline. Linking family stories and traditions from disparate learners enriches our understanding of ordinary lives in the period, but it also reflects priorities in personal, familial, and communal recollection. What is recollected and what is not? Are families more likely to rehearse Grandad's military exploits against the British-reflecting the official state history-while forgetting the grim financial price paid by other ancestors left unemployed by war or revolution? Such questions are useful when considering popular historical consciousness, state commemoration, and research funding.

Errors of fact and popular misconceptions appearing in learners' comments are also of value, allowing researchers to analyze how versions of history are constructed in the public mind. MOOC discussion forums enable us to gauge learners' reaction to new facts or to novel analyses of established historical events. By assessing the level of comfort with, or resistance to, new conceptions of history we learn much about the relationship between the academic discipline and popular awareness, and about the role of history in public discourse.

\section{The Irish Lives MOOC}

The MOOC examined in this research focuses on the revolutionary period between 1912 and 1923 in Ireland, and was delivered over six weeks by Trinity College Dublin, Ireland, and Futurelearn (see Figure 1 for details of the MOOC structure and homepage). The topic of the MOOC under discussion here, a period of great political and military upheaval in Ireland, is just beyond living memory but firmly within family memory. Thus it is recent enough, and significant enough, to have produced a wealth of primary sources, while also being beyond the realm of immediate politics-almost! So it can be argued 
that this time period, in many parts of the globe, would lend itself particularly well to discussion and contributions of new knowledge by the online community. Most learners were aware, to some degree, of debates over the meaning of the events during the revolutionary period, and well-publicized centenary anniversaries created a broader context for their discussions.
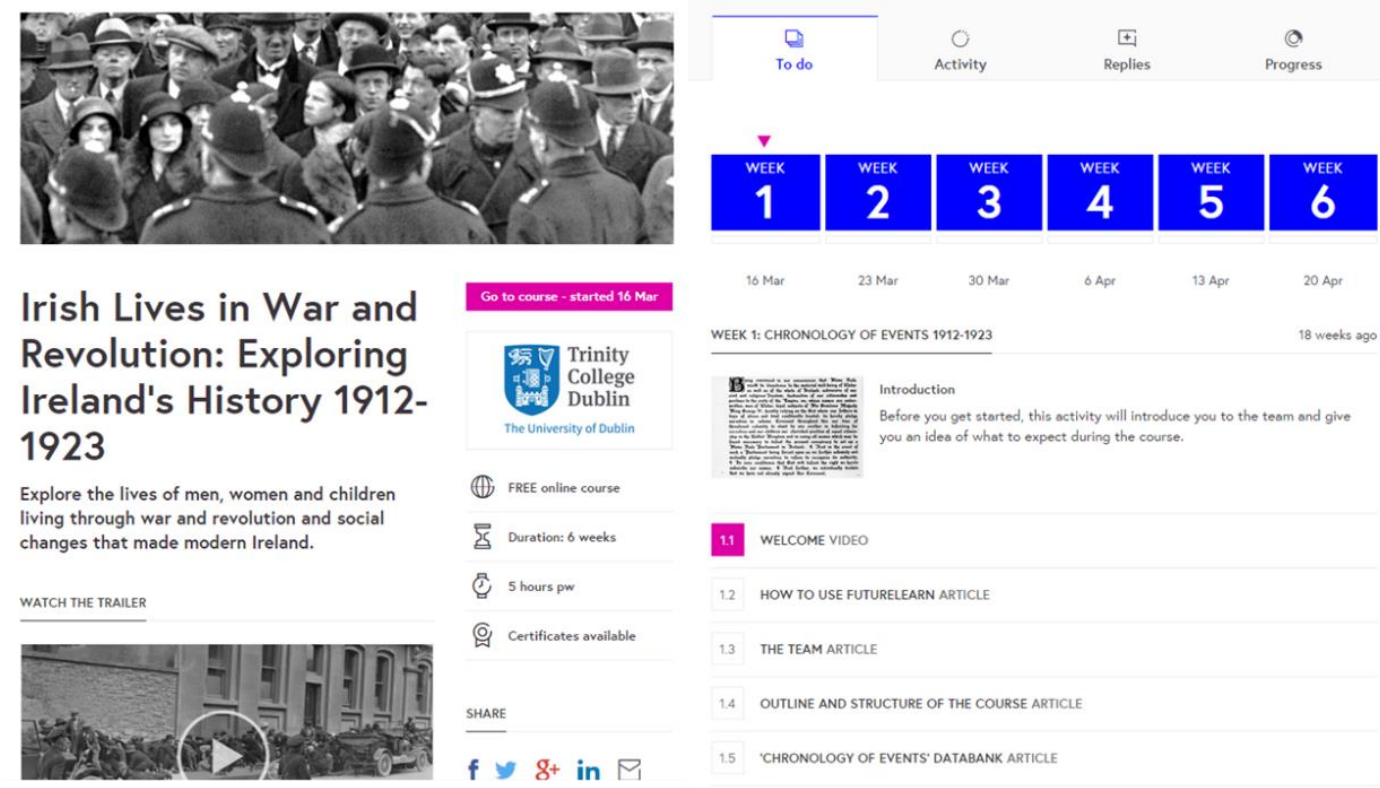

11.

WELCOME VIDEO

HOW TO USE FUTURELEARN ARTICLE

THE TEAM ARTICLE

OUTUNE AND STRUCTURE OF THE COURSE ARTICL

'CHRONOLOGY OF EVENTS' DATABANK ARTICLE

Figure 1. The Irish Lives MOOC home page and week one course outline.

The Constructivist model was chosen for this MOOC as the aim was to engage learners with the lived experience of ordinary people, and to arrive at their own conclusions. " This approach views education as an active and continuous process in which the student's learning is based on his or her personal understanding. On encountering new information students may provisionally accept it, or even reject it, as they construct their individual understanding. Thus what a student currently believes, whether correct or not, is important, and each student takes responsibility for their own learning (University College Dublin, 2016). Even when delivering the basic chronology in Week 1, the course design avoided long lists and rote learning, presenting instead composite characters representing a range of typical people and viewpoints from the period. This was somewhat risky from the perspective of pure history, and links were provided to traditional chronological lists, but learners clearly connected with the "characters" approach. Further research into the effectiveness of different teaching methods specifically for Humanities MOOCs might ascertain their value in promoting analytical thinking, perhaps reassuring reluctant educators that established classroom practice, and core values within the Humanities, still apply.

Rather than delivering a chronological narrative throughout the course, or presenting the learner with a firmly fixed analysis, the "Irish Lives" MOOC had the stated intention of presenting a wide range of personal experiences of the revolutionary period in Ireland. This open format empowered learners to risk expressing their own opinions and to share something as personal as a family tradition or memory in the discussion forum. The resources presented to learners in the MOOC in video and article format 
were available to learners for an unlimited period of time, and most resources remain accessible; however some images and video content will be removed after three years due to copyright issues.

\section{Research Aim}

This research aims to explore the potential of historical MOOCs for generating, extracting, and investigating personal historical narratives through qualitative thematic analysis. It is important to note that the purpose of the thematic analysis was to demonstrate how oral narratives can be extracted and used for further understanding of history, rather than for a rigorous analysis of thematic elements. It was used to provide a structure to the extraction, understanding and classification of the personal narratives and to argue for the generative power of MOOCs for oral histories. The key research questions of this study are to:

- RQ1: Explore the benefits of MOOCs for teaching and researching history, and in particular, for the field of Oral History.

- RQ2: Explore whether MOOCs can be used as a generative repository for Oral History narratives via learner comments.

\section{Methodology}

This research used a qualitative thematic analysis to identify, extract, classify, and explore personal historical narratives within learner comments in the Irish Lives in War and Revolution MOOC community. As part of the FutureLearn terms and conditions, individuals who register for the platform accept that their comments may be used for research purposes. The majority of MOOC studies have used a quantitative or mixed method methodological approach (Gasevic, Kovanovic, Joksimovic, \& Siemens, 2014; Raffaghelli \& Persico, 2014), and recent studies investigating MOOC community comments have commonly used quantitative methodologies (Rossi \& Gnawali, 2014; Wong, Pursel, Divinsky, \& Jansen, 2015). However, qualitative analysis can bring about a more detailed and nuanced understanding of learners that can be absent with a purely quantitative analysis. Previous qualitative studies which have employed thematic analysis within MOOCs have moved away from learner comments and have used learner blogs (Zutshi et al., 2013), MOOC videos (Hui, Yinjuan, Yingshan, \& Zenong, 2014), online surveys (Baxter \& Haycock, 2014), instructor observations (Grunewald et al., 2013), and twitter comments (Xia, 2014) to gain perspectives on MOOC learner behaviour and attitudes. Qualitative analyses of MOOC learner comments, via content or thematic analysis, have not been commonly implemented due to issues with scale, coding complexity, and the knowledge gap of investigating the content rather than the form of learner comments.

In order to streamline the qualitative analysis of personal narrative comments, a subset of comments was chosen relative to learner experiences of history at school. This sample was selected through a purposive criterion sampling approach. This sampling approach selects all cases that meet some predetermined criterion of importance (Palinkas et al., 2015). The three course instructors observed during the implementation of the MOOC that a substantial number of learners had provided personal narratives on learning history at school, and the theme was also contextually relevant to the MOOC itself (i.e., education). It must be noted that the learners were never asked to comment on their experiences at school explicitly, and these comments emerged from the community discussions in response to MOOC resources and to other learners. 
The sampling process began by downloading all learner comments from the six weeks of the course. The sample was then created by searching for the keyword "school," and all comments with this keyword extracted from the dataset and imported into NVivo 10. This software is commonly used for qualitative thematic analysis (Agosto \& Hughes-Hassell, 2006; Lingard, Reznick, DeVito, \& Espin, 2002; ZapataSepúlveda, López-Sánchez, \& Sánchez-Gómez, 2012) and although other forms of analysis tools such as Leximancer could be used, NVivo 10 was selected for its strengths in researcher-driven analysis rather than a more predictive approach (Sotiriadou, Brouwers, \& Le, 2014). A total of 1,306 comments were extracted from the MOOC learner dataset of 68,700 comments. Each of these comments was read to determine whether there were personal narratives within.

Personal narratives were determined as being comments written in the first person (i.e., I, me, my) that gave a narrative account of a personal experience at school or a personal experience of a family member. A total of 485 personal narratives related to school experiences were extracted (see Table 1 for details of sampling frequencies).

Table 1

Process of Sampling Personal Narratives from MOOC Learner Comments

\begin{tabular}{|l|l|}
\hline Total MOOC learner comments & 68,700 \\
\hline Total comments with "school" in the content & 1,306 \\
\hline Total comments identified as being a personal narrative related to "school" & 485 \\
\hline
\end{tabular}

An open approach to thematic analysis was then conducted over the sample of "school"-themed personal narratives. Open coding is the process of breaking down the data into distinct units of meaning by analyzing words and phrases and connecting them to the issue under investigation (Goulding, 1999). NVivo 10 was used to organize, code, and thematically structure the posts in terms of four major emergent themes (specific historical events or activities, positive perception of history at school, negative perception of history at school, and MOOC teaching compared with school experiences) and six minor themes (tediousness, inadequate teaching, biased teaching, new multimedia, learning from the lives of ordinary individuals, and peer learning). This emergent approach was conducted by two researchers and each segment of text was coded twice to ensure coding validity. The main rationale for this thematic analysis was to classify common personal narratives for better visibility and clarity of understanding.

\section{Results}

A total of 485 personal narratives from the Trinity College Dublin/Futurelearn "Irish Lives in War and Revolution" MOOC were thematically analyzed. An open approach to qualitative coding was adhered to, resulting in the emergence of thematic elements related to the school experiences of MOOC learners. 
A summary description of these themes and the content provided by MOOC learners is presented in the next section (see supplementary materials for full quantitative results).

\section{Thematic Results}

Narratives of Specific Historical Events at School. MOOC learners provided personal narratives of specific historical events when they were at school. One particular event that multiple learners $(n=5)$ commented on was the 5oth anniversary of the 1916 Easter Rising, in 1966. The learners gave descriptive accounts of their experiences of this event within their homes and schools and commented upon the songs they sung, parades they attended, and the clothes they wore. These narratives were generated both in response to resources provided about this event and also through social interaction with other learners who had similar experiences.

Negative Perception of History at School. Learners provided narratives of their experiences of learning history at school, many of which had negative words or themes attached to them $(n=212)$. These negatively themed narratives were sub-themed into three further themes: "tediousness of historical learning," "inadequate teaching," and "biased teaching." The theme "tediousness of historical learning" encompassed comments from learners who felt that their history schooling was boring, and that they were only told to learn facts, rather than to question or understand history. Many learners also felt that their history schooling was insufficient; these comments were themed as "inadequate teaching." Some felt that the historical information taught to them was selective, only focused on specific periods, and neglected teaching about the real lives of people. The third sub-theme, "biased teaching," described how learners felt that they were given sanitized, biased, or a narrow viewpoint of Irish history.

Positive Perception of History at School. Narrative descriptions of positive experiences of history at school also appeared $(n=18)$. These positive narratives included describing teachers who had an impact on their education, personal experiences of learning history, and feelings towards studying history at school. Examples of school trips to museums presented rich detailed descriptions of the experiences of children learning history during different time periods.

In addition to narratives that concentrated on their school experiences, many learners also compared their experiences with the MOOC teaching pedagogy.

MOOC Teaching Compared with School Teaching. In addition to generating personal narratives about their educational experiences, the learners also presented their thoughts on how the MOOC differed from their schooling. This theme was sub-themed into "use of new multimedia," "learning from the lives of ordinary individuals," and "peer learning."

Many learners commented on the effectiveness of video $(n=71)$ for encapsulating the poverty and fear of ordinary people during revolutionary times, compared with using only history books in school. They also commented on the breadth of material covered and how learners have a choice to focus on areas that interest them. A recurring comment within the sub-theme of "use of new multimedia" was how the digital sources, such as video, photo, audio, and contemporaneous documents, brought history to life $(n=88)$.

One of the key messages of the MOOC was to present history from the perspective of the lives of ordinary individuals. Learners commented that this differed from their historical schooling $(n=125)$ in that 
presenting information in this way helped them imagine what it would have been like to live during that era. Many felt that this connection with the experiences of ordinary individuals helped them understand complex historical issues in a new way $(\mathrm{n}=23)$.

Another key sub-theme that emerged was that of peer learning. Learners felt that discussing history with others within the MOOC discussion forum challenged and extended their ideas of history $(n=44)$. In essence, the MOOC invited them to think rather than just memorize historical facts.

Personal Narrative Generation. A key question that needs to be addressed, having explored the personal narratives, is how and why the narratives are generated, and what relevance does this have to the type of content being contributed by the learners? Four main pedagogical tools used in the MOOC were identified as being important for generating personal narratives: reflective questioning, multimedia resources, links to external repositories, and inter-learner interaction. These were identified holistically by linking the pedagogical tool to the personal narrative generated. The holistic method has been employed for understanding concepts as a whole by linking different types of information in a meaningful way using a reflexive and process-driven approach (Hesse-Biber \& Leavy, 2006; Ifenthaler \& Widanapathirana, 2014). Each comment was examined in turn and linked to the pedagogical tool that generated the comment. For example, comments that were generated from other learners were linked to the theme "inter-learner interaction."

These tools have been conceptualized as "direct generation" or "indirect generation" in order to aid comprehension and classification. Direct generation tools have stimulated shared learner narratives in direct response to a resource created by the MOOC instructors. Indirect generation tools, in contrast, have generated learner narratives in response to another learner. In effect, rather than being directly influenced by the MOOC content, an additional step (i.e., another learner) has been placed in between the MOOC content and the shared narrative. This delineation between the two types of generational tools describes how it is not just the MOOC resources that are encouraging shared narratives, but also that other learners are having an impact on this behaviour. Figure 2 describes this conceptualization of personal narrative generation in MOOCs.
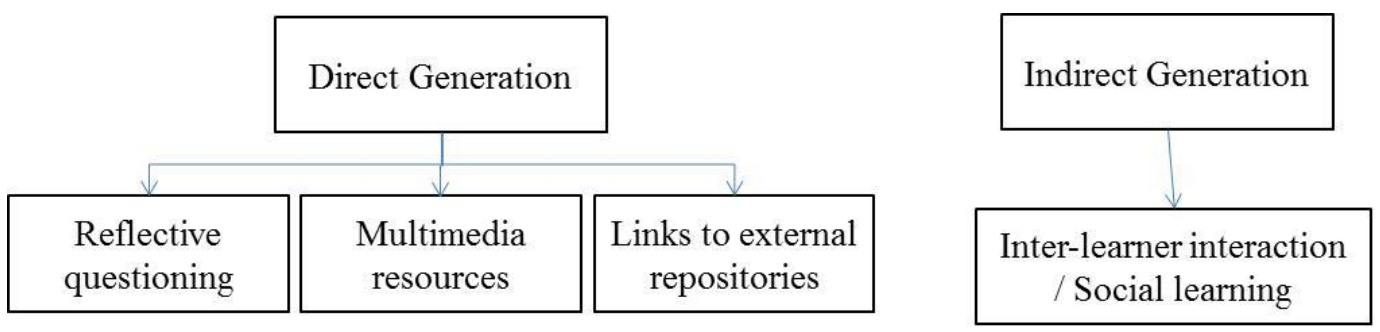

Figure 2. MOOC pedagogical tools that generate personal narratives.

This thematic analysis of learner comments, focusing on personal narratives of historical experiences at school, demonstrates that the MOOC has not only been a platform for learning history but also serves as a generative repository for personal historical narratives through MOOC resources and social interaction. These results broaden our understanding of MOOCs as being not only vehicles for historical learning, but also for presenting personal historical narratives. The implications of this are summarized in Figure 3 and are now discussed. 


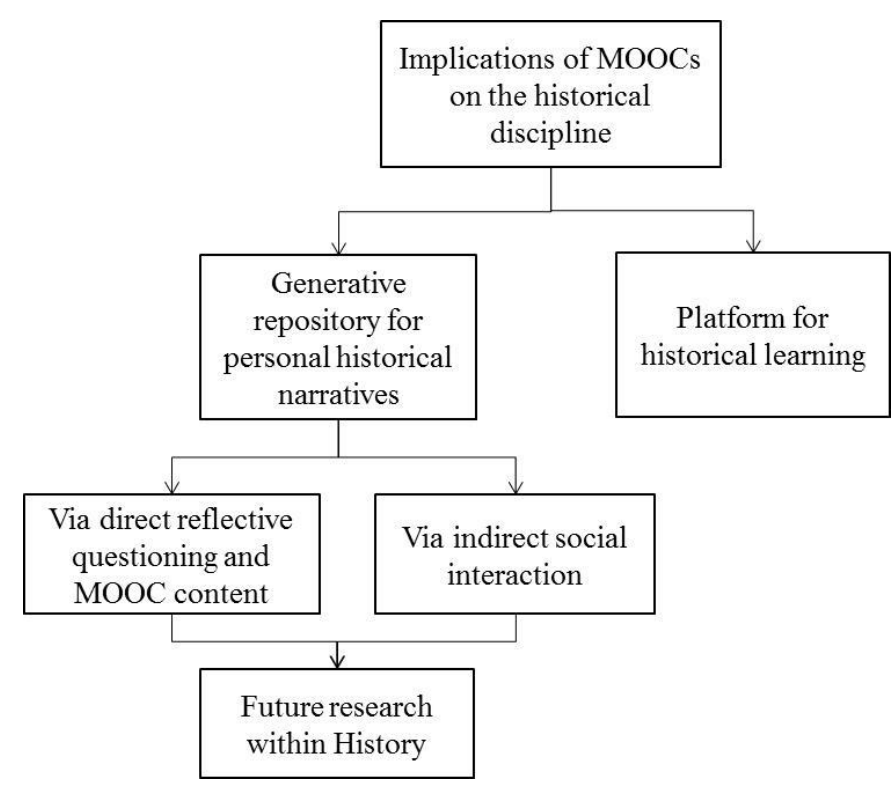

Figure 3. Implications of MOOCs on the historical discipline.

\section{Discussion and Further Study}

The qualitative analysis of learner interaction on the "Irish Lives in War and Revolution: 1912-1923" course shows that MOOCs can be an effective additional tool for teaching history and can also promote critical thinking. This addresses the first of our research questions. MOOC learners can come to understand their own family history or stories in the broader context, a central aim of all history teaching. But by welcoming large-scale contributions from the online community, the MOOC, uniquely, allows the learner to see that their family story is part of the fabric of history: that it counts as history. Their parents and grandparents may not have been public figures directing events and "making history," but they were also not just "victims" or subjects of history. They were the great majority of ordinary people whose lives were the stuff of history; all the trends, moods, votes, enlistments or non-enlistments in armies, contributions to causes, and communal sense of grief at all sorts of losses: and the sheer plodding survival comprise these hundreds of thousands of daily lives.

Learners can see others discussing, debating, explaining, and expanding upon some family story that they have chosen to share. Some express their incomprehension of elements of their family story-Why did Granny decide go to England in 1914? How did Grandad's shop do so well during the War of Independence?-while others suggest possible explanations based on the MOOC resources and on stories from their own families.

Through this course structure, teaching approach, and learner engagement, unexpectedly a history MOOC can also become a generative repository for personal historical narratives. Thus a well-designed history MOOC can act as a bridge, linking academic history teaching and research with popular history.

\section{Implications for Education and Historical Research}

The sample selected for this research, experiences at school, demonstrates how learners, without explicit guidance, provide personal narratives in response to historical resources and social interaction. 
The implications of this are significant for the Humanities. Learner interactions can be useful for considering historical consciousness that can guide Humanities research, funding, and commemorations. The learner comments also demonstrate the degree and context of public interest in historical knowledge, and can act as a sort of online ephemera collection, akin to physical collections in many large libraries. This research also suggests that, in creating a new digital resource for researchers, MOOC learner comments expand the realm of digital humanities, not only by generating searchable data in themselves but also a lens through which digital humanities researchers can analyze the public response to existing digital material.

Within the context of the comments analyzed, it was noted that many were related to negative experiences of history at school. These comments are striking as, despite their early negative encounter with the subject, these learners have signed-up to a history course, which indicates a very real appetite for knowledge and a persistent curiosity about the topic. A negative school experience may have many causes, including the attitude and approach taken by both pupil and teacher. It should also be noted that history teaching at primary and secondary level today is more engaging and student-centered than in the past. However, the contrast between these negative recollections and the positive response to the expansive nature of the MOOC, with the freedom it offers for individuals to pursue what interests them, supports the argument for MOOCs as a valuable educational tool in the Humanities.

Another key implication of this research is how personal narrative generation via MOOCs can have an impact on learning. Learners who present their own historical narratives are in effect augmenting the educational content, and providing additional and somewhat relatable information to other learners. Although further research is necessary, the presenting of narratives by learners could influence community engagement. Anecdotal evidence from the comments suggests that oral narratives often prompted longer discussions between multiple learners, with some experiencing the same historical event and reflecting with one another. Prompting learners to reveal their own narratives could have implications for community engagement, however it is unknown whether the implicit nature of how the MOOC learners presented such narratives would be repeated in a more explicit format. It is evident that narratives could be important within the online educational space, however further research is needed to ascertain in what way.

\section{MOOC Comments as Oral History or Public History?}

Oral History testimony involves audio recording and a precise transcription. As written text, MOOC contributions may not qualify, however, their immediacy, direct unmediated form, and "ordinary" authors separates them from official records and-arguably-from personal correspondence. Learner responses are more unstructured than those by participants in a formal Oral History project, where an interviewer follows a set questionnaire with varying degrees of flexibility. The physical location and level of attention among MOOC learners can vary widely, with comments being typed on a desktop PC on the kitchen table, on a tablet with the television on in the background, or on a mobile phone during the daily commute. But these factors do not necessarily invalidate the results. The communications technology used by MOOC learners has overtaken one of the challenges of Oral History: how to access your interviewees. Indeed the process may now be seen in reverse, as the public choose when and how to engage with the process, what topics to discuss, and what format their responses take.

As with formal Oral History, however, the casual comment can be the most rewarding. Indeed the informality of the discussion between learners can be more revealing than the structured approach of 
the traditional Oral Historian. Learners may respond to a direct question posed by the course tutors, but a random comment may spark off a long thread of discussions with others. Focused, as they generally are, on an element of the history MOOC, should such a thread be classified as Public History? By facilitating such "shared authority" the MOOC generates a new type of historical resource. ${ }^{1}$

Similarly, a learner may choose to comment on an individual item, photograph, or digitized text among the thousands available via the linked digital resources. Their choice, and the memories, narratives, and discussion that can flow from it, tell us much about what interests the learner audience at large. They may respond more vigorously to an image of a worried mother with her children, chosen by a fellowlearner, than to a more dramatic image of a military raid or a burning house presented by the course designers.

The freedom of choice provided by the MOOC, as it introduces thousands of learners to previously undiscovered digital sources, opens entirely new conversations. If lecturers seek to instill in university students the concept that history is constructed and contested, the MOOC's limitless range of sources promises much more construction and many more contested interpretations.

\section{Limitations}

Key differences exist between MOOC learner comments as a source, and traditional Oral History data; for instance, the sample is a self-selected population with a shared interest in history. Other limitations must also be kept in mind: demographic data from this MOOC described the majority of learners as being university educated and employed or retired.

Another limitation is the use of a sample of comments for exploring "oral" narratives: it would be more beneficial to have explored all of the themes emerging from all of these comments. Detailed analysis of large scale Oral History narrative comments can be a time-intensive approach, however, the use of automatic qualitative coding tools such as Leximancer to first determine the key historical themes emerging, before engaging with a detailed analysis with NVivo, could be a method of streamlining the process. This could help generalize the findings of this research in other disciplines.

\section{Future Research}

There is scope for interesting research into public perceptions of history in different cultures and nationalities, and among various demographic groups (considering, for example, age, gender, and educational attainment). Such research would be a valuable contribution to the field of Public History. Large amounts of taxpayers' money are spent on commemorative events internationally; Ireland is experiencing a "decade of centenaries" from 2013-2023, much of Western and Central Europe is marking the centenary of the Great War 1914-1918, and the many new independent states which it produced. MOOC-based research could help to measure the public response to such efforts, and also give voice to individual and familial narratives and memories that may not echo the official national memory. Further research would also inform the broader debate around Cultural Heritage, testing the success of policies pursued by the European Union, UNESCO, and other agencies.

In addition, this research has expanded the field of knowledge around Massive Online Open Research by describing how narratives from large cohorts of collaborative learners, facilitated by generative

${ }^{1}$ Michael Frisch's (1990) A Shared Authority: Essays on the Craft and Meaning of Oral and Public History tackled the same question in a pre-MOOC era. 
pedagogical tools, can contribute to the historical discipline. Future research should explore these narratives within multiple contexts to ascertain their potential in other disciplines: for example, Humanities, health care, business, and sociology.

\section{Conclusion}

This research has described how MOOCs have a dual impact within the historical discipline comprising a platform for Public History and also a generative repository for Oral History. The generation of personal narratives is facilitated both through the MOOC resources, and also through social interaction with other learners. The comments from MOOC learners are not only useful for evaluating, reviewing, and keeping track of how they are engaging with course material, but are also useful for gleaning knowledge about additional experiences. In effect, it is not just the discipline giving knowledge to the people, but people are giving knowledge to the discipline.

\section{References}

Agosto, D. E., \& Hughes-Hassell, S. (2006). Toward a model of the everyday life information needs of urban teenagers, part 1: Theoretical model. Journal of the American Society for Information Science and Technology, 57(10), 1394-1403. Retrieved from http://www.scopus.com/inward/record.url?eid=2-s2.0$33746894557 \&$ partnerID $=40 \& \mathrm{md} 5=160$ cbogcdd2e2becb1b24f $3392 \mathrm{~d} 17458$

Allison, J. (2008). History educators and the challenge of immersive pasts: a critical review of virtual reality "tools" and history pedagogy. Learning, Media and Technology, 33(4), 343-352. doi:10.1080/17439880802497099

Bage, G. (1997). How can we teach history through television? Journal of Educational Media, 23(2-3), 203-214. doi:10.1080/1358165970230208

Baxter, J., \& Haycock, J. (2014). Roles and student identities in online large course forums: Implications for practice. The International Review of Research in Open and Distributed Learning, 15(1). Retrieved from http://www.irrodl.org/index.php/irrodl/article/view/1593

Brinton, C., Chiang, M., Jain, S., Lam, H., Liu, Z., \& Wong, F. (2013). Learning about social learning in MOOCs: From statistical analysis to generative model. IEEE Transactions on Learning Technologies, 7(4), 346 - 359.

Burke, M., Kraut, R., \& Joyce, E. (2010). Membership claims and requests: Conversation-level newcomer socialization strategies in online groups. Small Group Research, 41(1), 4-40. doi:10.1177/1046496409351936

Cauvin, T., \& O'Neill, C. 'Negotiating public history in the Republic of Ireland: collaborative, applied and usable practices for the profession.' Historical Research, (forthcoming 2016).

Diver, P., \& Martinez, I. (2015). MOOCs as a massive research laboratory: opportunities and challenges. Distance Education, 31(1), 5-25. doi:10.1080/01587919.2015.1019968 
Ebben, M., \& Murphy, J. (2014). Unpacking MOOC scholarly discourse: a review of nascent MOOC scholarship. Learning, Media and Technology, 39(3), 328-345. doi:10.1080/17439884.2013.878352

Fini, A. (2009). The technological dimension of a massive open online course: The case of the CCKo8 course tools. International Review of Research in Open and Distance Learning, 1O(5). Retrieved from http://www.scopus.com/inward/record.url?eid=2-s2.079956312929\&partnerID $=40 \& m d 5=627$ aagd 999160 dc 4 acdefd 3 b7103b164

Firmin, R., Schiorring, E., Whitmer, J., Willett, T., Collins, E. D., \& Sujitparapitaya, S. (2014). Case study: using MOOCs for conventional college coursework. Distance Education, 35(2), 178201. doi:10.1080/01587919.2014.917707

Frisch, M. (1990). A shared authority: Essays on the craft and meaning of oral and public history. Albany, NY: State University of New York Press.

Galegher, J., Sproull, L., \& Kiesler, S. (1998). Legitimacy, authority, and community in electronic support groups. Written Communication, 15(4), 493-530.

Gallagher, S. E., \& Savage, T. (2016). Exploring learning objectives at scale through concept mapping of MOOC learner discussions. Paper presented at the EMOOCS 2016 European Stakeholder Summit on experiences and best practices in and around MOOCs Graz, Austria.

Gasevic, D., Kovanovic, V., Joksimovic, S., \& Siemens, G. (2014). Where is research on massive open online courses headed? A data analysis of the MOOC Research Initiative. The International Review of Research in Open and Distributed Learning, 15(5). Retrieved from http://www.irrodl.org/index.php/irrodl/article/view/1954

Gillani, N., \& Eynon, R. (2014). Communication patterns in Massively Open Online Courses. Internet and Higher Education, 23, 18-36.

Glance, D., Forsey, M., \& Riley, M. (2013). The pedagogical foundations of massive open online courses. First Monday, 18(5).

Goldberg, L. R., Bell, E., King, C., O'Mara, C., McInerney, F., Robinson, A., \& Vickers, J. (2015). Relationship between participants' level of education and engagement in their completion of the Understanding Dementia Massive Open Online Course Approaches to teaching and learning. BMC Medical Education, 15(1). doi:10.1186/s12909-015-0344-Z

Goulding, C. (1999). Grounded theory: Some reflections on paradigm, procedures and misconceptions, Working Paper Series June 1999. Telford, UK: University of Wolverhampton.

Grunewald, F., Mazandarani, E., Meinel, C., Teusner, R., Totschnig, M., \& Willems, C. (2013). OpenHPI-A case-study on the emergence of two learning communities. Paper presented at the IEEE Global Engineering Education Conference, EDUCON.

Hesse-Biber, S. N., \& Leavy, P. (2006). The practice of qualitative research. Thousand Oaks, CA: SAGE Publications. 
Hillis, P. (2008). Authentic learning and multimedia in history education. Learning, Media and Technology, 33(2), 87-99. doi:10.1080/17439880802097634

Huang, J., Dasgupta, A., Ghosh, A., Manning, J., \& Sanders, M. (2014). Superposter behaviour in MOOC forums. Paper presented at the Proceedings of the first ACM conference on Learning @ Scale conference, Atlanta, Georgia, USA.

Hui, D., Yinjuan, S., Yingshan, T., \& Zenong, Q. (2014, 27-29 Oct. 2014). How micro lecture videos trigger the motivation of learners of Coursera: A comparative study based on ARCS mode. Paper presented at the International Conference of Educational Innovation through Technology (EITT), Brisbane.

Ifenthaler, D., \& Widanapathirana, C. (2014). Development and validation of a learning analytics framework: Two case studies using support vector machines. Technology, Knowledge and Learning, 19(1), 221-240. doi:10.1007/s10758-014-9226-4

Kennedy, J. (2014). Characteristics of Massive Open Online Courses (MOOCs): A research review, 2009-2012. Journal of Interactive Online Learning, 13(1), 1-15. Retrieved from http://search.ebscohost.com/login.aspx?direct=true\&db=ofm\&AN=96164279\&site=ehostlive

Koutropoulos, A., Abajian, S. C., de Waard, I., Hogue, R., Keskin, N. Ö., \& Rodriguez, C. O. (2014). What tweets tell us about MOOC participation. International Journal of Emerging Technologies in Learning, 9(1), 8-21. doi:10.3991/ijet.v9i1.3316

Koutropoulos, A., Gallagher, M. S., Abajian, S. C., de Waard, I., Hogue, R. J., Keskin, N. O., \& Rodriguez, C. O. (2012). Emotive Vocabulary in MOOCs: Context \& Participant Retention. European Journal of Open, Distance and E-Learning.

Lingard, L., Reznick, R., DeVito, I., \& Espin, S. (2002). Forming professional identities on the health care team: Discursive constructions of the "other" in the operating room. Medical Education, 36(8), 728-734. Retrieved from http://www.scopus.com/inward/record.url?eid=2-s2.00036036372\&partnerID $=40 \& m d 5=0$ cb71950obe26386ec 4 fae8c $7 b 4 c 5 c f a$

Liyanagunawardena, T. R., Adams, A. A., \& Williams, S. A. (2013). MOOCs: A systematic study of the published literature 2008-2012. The International Review of Research in Open and Distance Learning, 14(3). Retrieved from http://www.irrodl.org/index.php/irrodl/article/view/1455/2531

Machado, M. A., Verghese, G., \& Peltola, T. (2014, 27-31 July 2014). Massive Open Online Research: An approach to deal with wicked problems. Paper presented at the Proceedings of PICMET '14 Conference: Portland International Center for Management of Engineering and Technology; Infrastructure and Service Integration.

Mackness, J., Waite, M., Roberts, G., \& Lovegrove, E. (2013). Learning in a small, task-oriented, connectivist MOOC: Pedagogical issues and implications for higher education. International Review of Research in Open and Distance Learning, 14(4), 140-159. Retrieved from 
http://www.scopus.com/inward/record.url?eid=2-s2.0-

84885340422\&partnerID $=40 \& \mathrm{md} 5=96 \mathrm{~d} 4 \mathrm{aeO} 2 \mathrm{f} 2526 \mathrm{f} 2 \mathrm{fceb} 5231 \mathrm{a} 32 \mathrm{c} 7 \mathrm{~d} 25 \mathrm{O}$

MOOC-List. (2015). MOOC List | A complete list of Massive Open Online Courses (free online courses) offered by the best universities and entities. MOOC List. Retrieved from http://www.mooc-list.com/

Nyhan, J., Flinn, A., \& Welsh, A. (2013). Oral History and the Hidden Histories project: towards histories of computing in the humanities. Literary and Linguistic Computing: The Journal of Digital Scholarship in the Humanities, 1-15.

Palinkas, L. A., Horwitz, S. M., Green, C. A., Wisdom, J. P., Duan, N., \& Hoagwood, K. (2015). Purposeful sampling for qualitative data collection and analysis in mixed method implementation research. Administration and Policy in Mental Health and Mental Health Services Research, 42(5), 533-544. Retrieved from http://link.springer.com/article/10.1007/s10488-013-0528-y

Perifanou, M. A. (2014). How to design and evaluate a Massive Open Online Course (MOOC) for language learning. Paper presented at the The International Scientific Conference eLearning and Software for Education.

Prpić, J., Melton, J., Taeihagh, A., \& Anderson, T. (2015). MOOCs and crowdsourcing: Massive courses and massive resources. First Monday, 20. Retrieved from http://firstmonday.org/ojs/index.php/fm/article/view/6143/5170

Raffaghelli, J., \& Persico, D. (2014). Methodological issues in research on MOOCs. Paper presented at the Proceedings of the European Conference on e-Learning, ECEL.

Rossi, L., \& Gnawali, O. (2014). Language independent analysis and classification of discussion threads in Coursera MOOC forums. Paper presented at the IEEE International Conference on Information Reuse and Integration, Redwood City, CA.

Samuel, R. (1996). Theatres of Memory: Past and Present in Contemporary Culture. London, UK: Verso.

Sangrà, A., González-Sanmamed, M., \& Anderson, T. (2015). Meta-analysis of the research about MOOC during 2013-2014. Educación XX1. doi:10.5944/educxx1.14451

Seaton, D. T., Bergner, Y., Chuang, I., Mitros, P., \& Pritchard, D. E. (2014). Who does what in a massive open online course? Communications of the ACM, 57(4), 58-65. doi:10.1145/2500876

Sotiriadou, P., Brouwers, J., \& Le, T.-A. (2014). Choosing a qualitative data analysis tool: a comparison of NVivo and Leximancer. Annals of Leisure Research, 17(2), 218-234. doi:10.1080/11745398.2014.902292

Tucker, C., Pursel, B. K., \& Divinsky, A. (2014). Mining student-generated textual data in MOOCs and quantifying their effects on student performance and learning outcomes. Computers in 
Education Journal, 5(4), 84-95. Retrieved from

http://www.scopus.com/inward/record.url?eid=2-s2.0-

84912525270\&partnerID $=40 \& m d 5=728$ de $30990 c 665$ d 21 fabc2b2c19a9 635

University College Dublin (2016) Constructivism and Social Constructivism in the Classroom.

Retrieved from

http://www.ucdoer.ie/index.php/Education_Theory/Constructivism_and_Social_Constructi vism_in_the_Classroom

Wang, Z., Chen, L., \& Anderson, T. (2014). A framework for interaction and cognitive engagement in connectivist learning contexts. The International Review of Research in Open and Distributed Learning, 15(2).

Wheeler, S., \& Gerver, R. (2015). Learning with "e"s: Educational theory and practice in the digital age. Bancyfelin, UK: Crown House Publishing.

Wong, J. S., Pursel, B., Divinsky, A., \& Jansen, B. J. (2015) An analysis of MOOC discussion forum interactions from the most active users. Vol. 9021. Lecture Notes in Computer Science (including subseries Lecture Notes in Artificial Intelligence and Lecture Notes in Bioinformatics) (pp. 452-457).

Xia, J. (2014). A content analysis of tweets about MOOC experiences. Ubiquitous Learning, 6(3), 1-14. Retrieved from http://www.scopus.com/inward/record.url?eid=2-s2.084922737644\&partnerID $=40 \&$ md $5=$ eb5ec4333586c4903bb97b306f2dcgeo

Zapata-Sepúlveda, P., López-Sánchez, F., \& Sánchez-Gómez, M. (2012). Content analysis research method with Nvivo-6 software in a PhD thesis: an approach to the long-term psychological effects on Chilean ex-prisoners survivors of experiences of torture and imprisonment. Quality and Quantity, 46(1), 379-390. doi:10.1007/s11135-011-9551-9

Zimmerman, C., Kopp, M., \& Ebner, M. (2016). How MOOCs can be used as an instrument of scientific research. Paper presented at the EMOOCS 2016 Proceedings of the European Stakeholder Summit on experiences and best practices in and around MOOCs.

Zutshi, S., O'Hare, S., \& Rodafinos, A. (2013). Experiences in MOOCs: The perspective of students. American Journal of Distance Education, 27(4), 218-227. doi:10.1080/08923647.2013.838067

\section{Athabasca} University

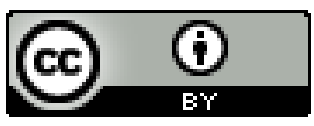

